\title{
Ethical, Legal, and Social Challenges in the Development and Implementation of Disaster Telemedicine
}

\author{
Christopher Tedeschi, MD, MA (1)
}

\section{ABSTRACT}

In recent years, advances in communications technology and market factors have led to a substantial expansion of telemedicine practice. One potential use of telemedicine is in disaster response, both as a resource for responders as well as a direct link to patients. The advantages of using telehealth to assist in disaster response are accompanied by important questions related to social impact, ethical implications, and regulatory oversight. A narrative review of several of these issues is presented here. The next steps in the development of a robust disaster telemedicine system will include the development of best practices and ethical guidelines agreed upon by all stakeholders, as well as the development of publicprivate partnerships geared at providing the highest quality disaster telemedicine to the greatest possible number of patients.

Key Words: delivery of health care, disasters, disaster medicine, health policy

$\mathrm{M}$ obile health technology has the potential to improve health care in many settings. Some authors have even suggested that "telehealth could transform the medical response" in disasters. ${ }^{1}$ Arguably, remote services, such as field triage, procedural guidance, mental health assessments, and expert consultations, could be implemented without the need to support additional on-site responders. ${ }^{2-4}$ Such a strategy could enlarge the pool of potential professional and volunteer providers.

Aside from issues related to logistics and communication infrastructure, other challenges will arise as disaster telemedicine evolves. Community involvement, regulatory structure, and elucidation of ethical standards will need to be addressed during the development process. While significant potential for disaster telehealth exists in the global setting, this discussion focuses on domestic US response.

\section{BACKGROUND AND RECENT EVENTS}

Telemedicine has been implemented in disaster settings for years. In 1985, the National Aeronautics and Space Administration (NASA) arranged a voice satellite communication link to assist with earthquake response in Mexico City. Soon after, the 1988 US-USSR "spacebridge" linked Armenian hospitals with US medical centers, including a unidirectional video link, following a devastating earthquake. ${ }^{5}$ In the wake of Hurricane Hugo in 1990, National Guard responders in the Virgin Islands transmitted locally acquired radiology images to military hospitals in the continental United States. ${ }^{5}$ Several other examples of disaster implementation of telemedicine have been described. ${ }^{4,6,7}$

The "serial hurricanes" of 2017 fueled interest in newer telemedicine models. In particular, directto-consumer (DTC) providers offered services to affected populations. ${ }^{8}$ In the 30 days following Hurricanes Harvey and Irma (August-September 2017), 1 DTC provider offered free 2 -way video visits to affected consumers. The service provided 1414 visits to Harvey victims and 644 to victims of Irma. ${ }^{6}$ Firsttime users comprised $63 \%$ of visits, due in part to a 2017 Texas law that eliminated the requirement that an in-person visit was needed to establish a patientphysician relationship. ${ }^{6,9}$

Following Hurricane Irma, 1 Florida health system reported a more than $500 \%$ increase in downloads of its telemedicine smartphone app, whereas another hospital reported 2700 new telemedicine users in a 3 -day period. ${ }^{10}$ At least 1 academic medical center (the author's institution) implemented telemedicine specialist consultation from Puerto Rico during the response to Hurricane Maria in 2017. ${ }^{11}$

\section{METHODS}

In order to create a narrative review of the ethical, legal, and social issues related to disaster telemedicine and the implications of those issues, the academic 
literature related to disaster and telemedicine ethics, telemedicine in disasters, and legal aspects of telemedicine practice was searched using the PubMed database for articles published up until early 2019. Online search engines were used to identify gray literature related to the same topics during the same time period. A critical analysis of the relevant data was constructed, and suggestions for future work in the field were developed.

\section{SOCIAL IMPACT OF DISASTER TELEMEDICINE RESPONSE Advantages and Potential Uses}

Potential uses of disaster telemedicine include remote consultation, as well as direct patient care. ${ }^{5,12,13}$ While the implementation of tele-response may not be as advantageous in the acute stage of a disaster, the potential impact is potentially greater after the first 48 hours, in the days and weeks of subacute response and early recovery.

Disaster tele-response could include novel applications, such as consultation for inpatients, intensive care unit (ICU) patients, or residents of long-term care facilities, potentially circumventing the need to transfer vulnerable patients in dangerous situations, or even the evacuation of entire facilities. Acquisition of clinical data by first responders (eg, ultrasound, electrocardiograms) for remote interpretation could inform triage decisions, as well as specialist care at field hospitals or other resource-limited locations.

In a well-developed system, a "telemedicine hub" for disaster response could connect available telemedical infrastructure with users at peripheral sites. While it may be difficult to quantify the benefits associated with such a system, evidence suggests that a regional hub may be able to offer telemedical specialty care to patients early in their hospital stay after a disaster, augmenting surge capacity by reducing wait times and need for transfers. ${ }^{14}$ Such systematized "spoke and hub" systems could tap expert resources outside of local geographic areas, for example, burn care, poison control, or other resources of academic medical centers (www.ncbi.nlm.nih.gov/books/ NBK201063/).

\section{Evolution of Technology}

One principle in the implementation of new technologies is the participation of "end users" during the development process. ${ }^{15}$ Input from potential beneficiaries (clinicians and patients alike) helps shape system development. Furthermore, in any disaster setting, ethics, equity, and issues of human dignity are "fragile commodities" that warrant a close analysis in the context of introduction of a new model of care. ${ }^{15}$ Acceptance at the community level (and an understanding that disaster telemedicine may ultimately be considered standard of care) could help establish best practices. Ultimately, some system of quality assurance and quality improvement geared to the disaster setting could be developed.
As emergency plans affect entire communities, public acceptance in the development and implementation of a plan helps sustain public trust via inclusivity and transparency. ${ }^{16}$ Practically, this could include surveying communities about their attitudes toward disaster telehealth, and allowing potential beneficiaries of the technology to participate in its development. Such participation could foster a culture of acceptance in which communities feel assured that disaster telemedicine is not implemented with the primary intent of selling commercial services, coercing patients, or restricting care to select populations - all of which would be potentially unacceptable if applied during disasters via other modalities.

The manner in which a technology is developed and implemented shapes the environment of care and illustrates value judgments about priorities for use: telehealth innovators may choose to develop systems best suited to trauma, mental health, or obstetric evaluations, for example, but technical limitations may not allow optimization of all functions simultaneously. Each choice belies value judgments about the best ways to implement telemedicine technology and who might benefit, and warrants explicit consideration prior to "hard wiring" certain capabilities into the response infrastructure.

\section{Practice Standards}

In any setting, a telemedicine interface may alter clinical behavior. Data suggest that telemedicine patients' satisfaction rates are higher when prescribed antibiotics, ${ }^{17}$ and that telemedicine visits are shorter when antibiotics are prescribed, compared with non-antibiotic prescriptions or no prescriptions at all. ${ }^{18}$ Awareness of these phenomena could potentially alter telemedicine practice patterns. Relatively few studies have examined the effect of the telemedicine space on doctor-patient communication, potential medical errors, or practice variation.

Conceivably, such differences could be amplified by the tenuous connectivity of austere locations and episodic nature of the doctor-patient relationship found even in face-to-face care during emergencies. In some cases (such as DTC models), the potential habituation to the provision of prescription medications could be at odds with resource-limited emergency situations, in which medications may represent a scarcer resource than they do in routine practice. Awareness of such tendencies may help telemedicine providers adapt their practice to emergencies.

The physical (and psychological) distance implicit in the telemedicine interaction also seems exaggerated in a disaster setting, in which a patient is not at home or in an exam room but potentially in an improvised care location. Disaster telehealth responders will need to accommodate this distance in order to make recommendations that are practical and situationsensitive. Standard of care implies what a reasonable physician 


\begin{tabular}{|c|c|}
\hline \multicolumn{2}{|c|}{$\begin{array}{l}\text { Representative Social Challenges in the Development of } \\
\text { Disaster Telemedicine }\end{array}$} \\
\hline Issue & Concerns and Opportunities \\
\hline Community participation & $\begin{array}{l}\text { End users, such as patients and } \\
\text { clinicians, benefit from having a say in } \\
\text { the development of new technologies. } \\
\text { Active participation in systems } \\
\text { development helps facilitate informed } \\
\text { decision-making when a system is } \\
\text { implemented. }\end{array}$ \\
\hline Standards of care & $\begin{array}{l}\text { Disaster telemedicine providers need to } \\
\text { understand the limited resources of } \\
\text { affected communities and may need to } \\
\text { deviate from a customary standard of } \\
\text { telemedicine care while still having a } \\
\text { positive impact. }\end{array}$ \\
\hline Equity of accessibility & $\begin{array}{l}\text { Telemedicine practice assumes some } \\
\text { technological infrastructure, such as } \\
\text { broadband Internet. Providers will need } \\
\text { to account for inconsistencies in } \\
\text { availability of technology, especially as } \\
\text { they may affect vulnerable populations } \\
\text { with less robust ability to connect. }\end{array}$ \\
\hline Doctor-patient relationship & $\begin{array}{l}\text { The nature of the doctor-patient } \\
\text { relationship may be strained in all } \\
\text { telemedicine systems, and this may be } \\
\text { magnified in disaster situations. }\end{array}$ \\
\hline Tele-responders & $\begin{array}{l}\text { Remote disaster responders constitute a } \\
\text { novel group of health care providers. } \\
\text { Their educational, professional, and } \\
\text { psychological needs will be defined as } \\
\text { tele-response systems develop. }\end{array}$ \\
\hline
\end{tabular}

would do in a situation with similar resources, ${ }^{19}$ but this standard could be a challenge to accommodate in a DTC consultation if the remote provider is unaware of which resources are reasonably available (eg, pharmacies, refrigeration, transportation).

Some social challenges in the development of the technology are listed in Table 1.

\section{Connectivity}

Some combination of cellular service, Internet access, or satellite communication will define the capability of responders. Some DTC models rely on consumer access to such technology, which clearly could be limited during situations with compromised infrastructure.

Telecommunications infrastructure distribution in the United States is heterogeneous, and potentially less available in areas susceptible to extreme weather or other disasters. Census data of 2013 indicate a wide variance in access to broadband Internet; $80 \%$ of households in Massachusetts had broadband access, for example, compared with $57 \%$ in Mississippi. The same data also indicate that nearly 25 million households had no access to the Internet whatsoever, at home or elsewhere. ${ }^{20}$ Those populations without easy access may find telemedicine disaster care relatively unattainable. Yet disaster tele-responders, especially commercial entities, may inaccurately assume that Internet access is widely available even in the penumbra of a hurricane or earthquake. As disaster telemedicine becomes more mainstream (rather than an "added bonus"), care providers will be challenged to ensure that telehealth visits are available to an affected population, despite fairly substantial differences in infrastructure.

\section{Physician-Patient Relationship}

Some authors have argued that the physical proximity lost in the telemedical encounter may contribute to a sacrifice of the efficacy of the therapeutic relationship, and furthermore that the connection of touch, smell, and physical presence is an important source of moral responsibility. ${ }^{21}$ In a disaster setting, while the physical distance between doctor and patient may be no greater than in a routine televisit, the unique environment could increase the psychological distance between caregiver and patient. Aiming to provide real-time videoconferencing rather than other less direct means of provider-patient communication could help ameliorate this distance and maintain an acceptable degree of trust in a new doctor-patient relationship. ${ }^{22}$

\section{Tele-responders}

Some consideration ought to be given to tele-responders themselves. As tele-response becomes more commonplace, questions regarding both regulation and licensing (see the next section), as well as qualifications, vetting, and certification may become more relevant.

The criteria for becoming a "tele-responder," which may depend more on connectivity and communication than physical fitness or experience in austere settings, have not been well defined. Tele-responders would ideally have prior training in disaster response, as well as telemedical practice prior to responding to an event. Medical students have increasing opportunities to learn about telemedicine; in 2013-2014, $35 \%$ of US medical schools included telemedicine in a required course, which increased to $66 \%$ in $2017-2018 .{ }^{23}$ It is unclear, however, whether that content includes a discussion of emergencies or disasters. Additionally, an introduction to telemedicine practice could be included in training opportunities geared to first responders (eg, Federal Emergency Management Agency [FEMA] training courses, National Medical Disaster System [NDMS] teaching modules, or training for humanitarian responders).

Finally, the psychological impact of disaster response on any responder may be significant, and it is uncertain about how a digital interface may either mitigate this impact or possibly introduce new concerns related to clinicians who provide disaster care from the comfort of their homes and offices. 


Representative Legal and Regulatory Issues in the
Development of Disaster Telemedicine
$\begin{aligned} & \text { Issue } \\ & \text { Licensing and } \\ & \text { reciprocity }\end{aligned}$
$\begin{aligned} & \text { Telemedicine providers generally need to be } \\ & \text { licensed in the state in which the patient is located. } \\ & \text { Reciprocity of licensing could come from new } \\ & \text { models, such as the Interstate Medical Licensure } \\ & \text { Compact, or licensing rules specific to } \\ & \text { telemedicine. Providers acting on behalf of the } \\ & \text { federal government or as part of an EMAC } \\ & \text { agreement are generally recognized to have } \\ & \text { licensure in the state receiving assistance. } \\ & \text { Telemedical practice is governed by HIPAA } \\ & \text { regulations, although disaster situations may allow } \\ & \text { some relaxation of privacy standards. The nature } \\ & \text { of the telemedical interface poses unique risks to } \\ & \text { privacy that will require the development of } \\ & \text { mitigation strategies. }\end{aligned}$

Nonetheless, there is a clear advantage to having tele-responders add capacity to any emergency response without the inherent risks of being on-site. Caregivers working from distant locations will not require the food, shelter, and infrastructure support required at the scene, enabling these critical resources to be appropriately distributed elsewhere.

\section{LEGAL AND REGULATORY CONSIDERATIONS}

The dynamic legal and regulatory climate surrounding the routine practice of telemedicine has been described elsewhere. ${ }^{24}$ In disaster settings, the same issues can become more complicated or more urgent. Some relevant considerations are listed in Table 2.

\section{Licensing and Interstate Practice}

As of January 2018, 49 state medical boards, as well as the boards of Washington DC, Puerto Rico, and the Virgin Islands, required that physicians engaging in telemedicine be licensed in the state in which the patient is located. Some states offer telemedicine-specific certificates or licenses to practice medicine across state lines. ${ }^{25}$ While many issues regarding regulation and credentialing are common to all telemedicine practice, implementing services on short notice will require advance planning.

Tele-responders must rapidly understand the regulations relevant to the location in which patients are located, and assess the impact of those regulations on the care provided. In connections that cross state lines, such determinations may be difficult or uncertain. State laws would likely stipulate that providers be licensed in the state from which the patient is accessing care, even if the patient is not a resident of that state. ${ }^{3}$
Interstate response operations could ultimately be simplified by cross-state licensing or reciprocity pacts. The American College of Emergency Physicians (ACEP) "supports legislative efforts that would allow single-state licensing to be sufficient for telemedical practice throughout the United States." Deployment of tele-responders could potentially be made easier by the establishment of rosters of providers with multiple applicable state licenses, or pre-identifying providers registered via the Interstate Medical Licensure Compact (IMLC), an agreement which allows portability of medical licensure among participant states. ${ }^{27}$ As of late 2019, the IMLC agreement included 29 states, the District of Columbia, and 1 territory. ${ }^{28} \mathrm{~A}$ more robust adoption of such agreements could ultimately make identification of appropriate tele-responders more efficient after acute events.

Mutual aid agreements between states are governed in part by the Emergency Management Assistance Compact (EMAC). EMAC is an all-disciplines mutual aid agreement that enables state-to-state assistance during governordeclared states of emergency. All 50 states, as well as the District of Columbia, Puerto Rico, Guam, and the US Virgin Islands have enacted legislation to become EMAC members. ${ }^{29}$ The agreement stipulates that responders using their professional skills at the request of another state under the auspices of EMAC "shall be deemed licensed, certified, or permitted by the state requesting assistance to render aid involving such skill to meet a declared emergency or disaster." ${ }^{30}$

Presumably, this stipulation applies to physicians, nurses, and other licensed providers responding in person as part of an EMAC request. The extent to which EMAC applies to private-sector practitioners is unclear, as it generally applies to government resources and does not directly ensure licensure for private-sector professionals (eg, volunteers who seek to render aid independently or via non-governmental organizations). Alternative pathways also may apply - as of 2007, 32 states had statutes specifically granting licensure for volunteer physicians during a disaster or public health emergency, either via an expedited licensing process or through an exemptionreciprocity system. ${ }^{31}$ Alternatively, licensed professionals who are "federalized" during a disaster as members of disaster medical assistance teams (DMATs) or via the US Public Health Service do not require state licensure. ${ }^{31}$

In each case, the applicability to responders participating via telemedicine remains unclear, although the existing structure may suggest opportunities to develop tele-response as part of the current system (see the next section).

\section{Privacy and Confidentiality}

Privacy and confidentiality remain integral to the patient encounter in both telemedicine and disaster settings, and certainly in the confluence of the two. The telemedicine interface can pose risks to both privacy and confidentiality. ${ }^{32}$ Logistic 
limitations in disaster telemedicine could compromise patient privacy, whether related to the setting in which the care is delivered (eg, a crowded field hospital or emergency department without private space) or to the technology involved (exposing patient interactions to technicians, translators, etc.). Similarly, the data sharing or transmission necessitated by telemedicine link could jeopardize confidentiality, either at the time of transmission or as part of a subsequent electronic record. The unique privacy concerns related to disaster telemedicine have not been clearly elucidated but warrant closer attention as the technology develops.

Best practices for US-based telemedicine embrace the Health Insurance Portability and Accountability Act (HIPAA)compliance, and a variety of commercial platforms have been developed to allow practitioners to conduct virtual patient visits in accordance with the law. ${ }^{33}$ Disaster-focused models of care implemented domestically would need to take HIPAA regulations into account, whether undertaken by commercial entities or as part of a public sector response, that is, operated by state or local agencies or as part of the NDMS. While maintenance of privacy remains a primary goal in any clinical encounter, HIPAA allows for some patient information to be shared to assist disaster relief efforts. In certain circumstances, the Department of Health and Human Services (HHS) has issued waivers to further loosen privacy requirements, including the requirement to distribute a notice of privacy practices and the requirement to obtain patient agreement to speak with family members or friends involved in a patient's care. ${ }^{34}$ Similar waivers could facilitate telemedicine response in resource-limited settings.

\section{ETHICAL CHALLENGES}

Addressing ethical questions related to disaster telemedicine warrants a consideration of disaster ethics, in general, as well as issues related to telehealth, before integrating the two. A summary of ethical issues in disaster preparedness, response, and recovery is beyond the scope of this review, but those issues that seem most relevant to tele-response are introduced here.

The ethical principles specific to both emergency and disaster medicine, and telemedicine practice, have been reviewed elsewhere. ${ }^{21,32,35}$ Fundamental principles relevant in both settings include autonomy, beneficence, nonmaleficence, and justice. Patient rights are generally understood to include confidentiality, privacy, and continuity of care. ${ }^{36}$ Each of these principles may be challenged while providing remote care to vulnerable individuals. ACEP policy generally mirrors the provisions for ethical care of the emergency patient, in general, including privacy and confidentiality; provision of services regardless of race, religion, or ability to pay; established process of informed consent; and the development of quality assurance standards. ${ }^{26}$ Some potential ethical challenges are listed in Table 3.

\section{TABLE 3}

\begin{tabular}{|l}
\hline $\begin{array}{l}\text { Representative Ethical Challenges in the Development of } \\
\text { Disaster Telemedicine }\end{array}$ \\
$\begin{array}{l}\text { Ethical Principle } \\
\text { Autonomy }\end{array}$ \\
$\begin{array}{l}\text { Patients have the right to make informed } \\
\text { decisions about their care, which involves an } \\
\text { understanding of how telemedicine works. } \\
\text { Patient expression of autonomy by choosing a } \\
\text { modality of care may be tempered by efforts to } \\
\text { maximize the benefit to all affected persons. } \\
\text { Disaster telemedicine systems should be } \\
\text { engineered to maximize the value of the care } \\
\text { delivered to a community. This may include } \\
\text { offering telemedical care to a select group of } \\
\text { patients. Additional benefit comes from the use } \\
\text { of peer consultations for on-site providers. } \\
\text { New technologies may introduce harm. Risks in } \\
\text { disaster telemedicine include participation of } \\
\text { unqualified providers, patient abandonment, } \\
\text { or the use of the technology to further } \\
\text { secondary commercial or academic goals. } \\
\text { As a limited resource, telemedical emergency } \\
\text { care in disasters should be distributed } \\
\text { equitably, without regard for ability to pay or } \\
\text { other discretionary characteristics. Industry } \\
\text { best practices could ultimately address } \\
\text { commercial entities, as well as nonprofit and } \\
\text { government-supported providers. }\end{array}$ \\
Justice
\end{tabular}

\section{Autonomy}

In situations in which resources are not unduly constrained, the principle of autonomy plays a central role in medical decisionmaking. Patients have the right to make informed medical decisions for themselves, without health care providers attempting to influence their decisions. Discussions of patient autonomy often focus on the right to refuse care, but in a resource-limited situation may include the need to respect autonomous decisions to seek care elsewhere, to choose to which facility they may be transferred, or opt for an "in-person" provider rather than a tele-responder (although such decisions may be at odds with doing the greatest good for the greatest number of patients). Ultimately, autonomous decisions require both competence and informed consent, ${ }^{37}$ both of which may be challenging to ensure via a telemedicine link in a disaster situation. As noted earlier, a sufficient degree of community acceptance and participation in disaster care models could help ensure that patients make autonomous decisions during emergencies, by facilitating some degree of informed consent prior to an actual event.

\section{Beneficence}

Medical care during disasters ought to aim to do good for the individual patients involved and, ultimately, for a community. In a resource-limited setting, the utilitarian imperative may justify the use of telemedicine to free other "on the ground" resources to care for more acute patients. Such an undertaking, however, would need to ensure that tele-providers can offer 
the appropriate skills and knowledge and are using telemedicine (or any treatment modality) primarily for the benefit of the patient and not to further any commercial, research, or educational interest. In "peer-to-peer" models, additional benefit could arise from using expert consultants to supplement the efficacy of providers at the site of an event.

\section{Nonmaleficence}

The introduction of any new treatment or technology introduces the possibility of doing harm. Ultimately, the goal of responders (or tele-responders) is to perform to the best of their abilities without intentionally causing harm. ${ }^{19}$ As professional and regulatory bodies develop standards of care for disaster telemedicine, particular situations in which harm may be done will need to be addressed. Academics and practitioners may identify potential harms associated with disaster telemedicine, including, but not limited to, patient abandonment following brief or isolated visits, errors in diagnosis or medical decisionmaking due to the nature of the technological interface, or simply the denial of more appropriate in-person care due to the fact that the patient was selected for a telemedicine visit. Disaster telemedicine patients may be at increased risk of more subtle harm as well, including inappropriate care due to language or cultural barriers, or initiation of treatment plans without appropriate informed consent. A consensus statement or policy by key stakeholders in disaster response and telemedicine alike would help mitigate the risk of harm due to unintended consequences, or worse, opportunistic utilization of telehealth technology during emergencies.

\section{Justice}

Ethical guidelines for disaster care suggest that unavoidable differences in treatment be based on "appropriate differences among individuals" (see www.ncbi.nlm.nih.gov/books/ NBK201063/). Disasters are resource-limited situations. As such, disaster telecare itself ought to be considered a limited resource and therefore be subject to fair and equitable (although not necessarily equal) distribution. ${ }^{19}$ Disaster telehealth providers may need to consider how to distribute a particular resource, for example, specialist consultation, in as equitable a manner as possible in the face of infrastructure limitations or inconsistencies that limit the use of certain technologies in particular locations.

Similarly, if telemedicine is to be considered a fundamental part of disaster response, then the principle of equity implies that access to services should not be based on income or other discretionary characteristics. During the response to Hurricane Harvey, commercial telemedicine providers offered free consultations to patients affected by the hurricane, with a 1-per-person, 1-time use policy. ${ }^{38,39}$ While superficially generous, such an offer risks creating a situation in which patients who could not afford subsequent visits found themselves functionally abandoned, despite a potential need for follow-up or in the face of worsening symptoms.

\section{Fidelity}

Fidelity can be understood as the obligation to put patient welfare above other interests, while minimizing conflicts of interest or bias. ${ }^{40,41}$ In the case of disaster telemedicine, this may mean developing safeguards against commercial entities whose primary goal is to generate business in the wake of a disaster, or by an entity initiating telemedicine interactions rather than in-person care in order to facilitate the growth of a telehealth system or establish proof-of-concept in remote or austere settings.

The Council of Ethical and Judicial Affairs of the American Medical Association stresses the need to "match the mode of care to the patient," emphasizing that telemedical care could be appropriate in settings in which in-person care would be marginally better but logistically impossible (eg, outer space). ${ }^{40}$ Some disaster environments fit this category. Modifying the level of care during a disaster may certainly be justified in resource-constrained situations. Resources may be distributed unequally, inasmuch as decisions about distribution of resources are based on "appropriate differences" related to greater utilitarian goals. This acceptability of best available care could ultimately be at odds with concerns in the humanitarian setting where a "something is better than nothing" attitude may be perceived as harmful. ${ }^{42}$ For example, it would likely not be appropriate for a cadre of unsupervised medical students to provide disaster tele-response even if the recipients of that care might not have access to any care whatsoever otherwise.

\section{DISCUSSION - FUTURE MODELS OF CARE Commercial Providers}

As described, DTC telemedicine providers have already created a small but growing footprint in post-disaster care. As state telemedicine regulations become more permissive, the regulatory and technological barriers for DTC entities providing telemedicine during disasters may decrease. DTC models allow a larger degree of patient choice and autonomy in an open market, albeit limited by access to technology. Such robust growth will necessarily be balanced by concerns related to some of the legal and ethical issues already discussed. These risks could be mitigated by the development of industry best practices, agreed on by telemedicine providers in both the public and private sectors.

\section{Telehealth as Part of the State and Federal Response}

Under the auspices of the HHS, NDMS coordinates the nation's medical response during disasters and public health emergencies. NDMS oversees the nation's DMATs which can be rapidly deployed to disaster zones. The standards of care routinely offered by NDMS providers ideally represent a best practice for state and federal response to US disasters.

NDMS does not routinely offer telemedicine services as part of a disaster response but, as tele-response becomes more technically feasible, communities might expect that NDMS 
include peer-to-peer "consultation" telemedicine services or (less likely) direct telemedicine interactions between NDMS providers and patients.

In this federalized system, issues of licensing, liability, and questions related to the need to develop a formal doctor-patient relationship are circumvented. DMAT providers are permitted to provide direct patient care regardless of jurisdiction. One might imagine a federalized DMAT member responding remotely as part of a DMAT, fully supported by the NDMS.

Clearly, such a system would require investment in infrastructure, training, and provider recruitment. HHS has acknowledged that the 2017 hurricane season "stretched our resources almost to the breaking point" and has indicated that system enhancements could include reliance on privatesector partners, as well as an intention to increase the number of available providers by $2500 . .^{43}$ In a system in which telemedicine response is understood to be part of standard practice, some of that increased number of responders could potentially be a telemedicine workforce.

\section{Public-Private Partnership Via NDMS and EMAC}

After the serial hurricanes of 2017, HHS's office of the Assistant Secretary for Preparedness and Response indicated that it would increase capacity and investigate options for a public-private partnership. ${ }^{43}$ HHS also acknowledged that increased reliance on state EMAC resources could contribute to improvements in the NDMS. ${ }^{43}$ Private entities, such as academic medical centers or large health systems, many of which have already robust telemedicine networks, could potentially mobilize these resources as part of an EMAC response, again circumventing issues related to licensure and oversight that commercial endeavors might encounter. Several states have provisions under which private sector assets or volunteers can be made agents of the state for the purposes of an EMAC deployment. ${ }^{44}$

Conceivably, such an expansion of services could include the deployment of telemedicine capability with DMATs in which caregivers at the remote end of a telemedicine link are DMAT members or EMAC-certified partners, such as providers from local agencies, community hospitals, or academic medical centers. The development of such a system would require political will on the part of both the federal and state agencies, as well as further elucidation of issues related to licensing and standards of care.

\section{CONCLUSION}

The rapid evolution of technology and changing models of care have fueled a renewed interest in the development of disaster telemedical systems. Such an evolution is accompanied by important social, ethical, and legal challenges. Specific goals for further discussion ought to include the articulation of an ethical framework specific to telemedicine practiced under crisis standards of care, as well as a forum for the development of best practices and quality assurance measures specific to disaster telehealth. Community participation in the development of these standards should be emphasized.

Public-private partnerships have great potential for enabling widespread use of disaster telemedicine, both within existing federal and state response structures and via novel commercial or nonprofit providers. Ultimately, such engagement and partnerships will help lay the foundation of an organized, effective, and equitable disaster telemedicine infrastructure.

\section{About the Author}

Department of Emergency Medicine, Columbia University Vagelos College of Physicians and Surgeons, New York, NY (Dr Tedeschi).

Correspondence and reprint requests to Christopher Tedeschi, Department of Emergency Medicine, Columbia University Vagelos College of Physicians and Surgeons, 622 West 168th Street, VC 260, New York, NY 10032 (e-mail: ct2122@cumc.columbia.edu).

\section{Conflict of Interest Statement}

The author has no conflict of interest to declare.

\section{REFERENCES}

1. Lurie N, Carr BG. The role of telehealth in the medical response to disasters. JAMA Intern Med. 2018;178(6):745-746.

2. Burke RV, Berg BM, Vee P, et al. Using robotic telecommunications to triage pediatric disaster victims. J Pediatr Surg. 2012;47:221-224.

3. Davidsen BS. Considerations when treating natural disaster victims through telemental/telebehavioral health programs. TechHealth Perspectives. Published 2017. https://www.techhealthperspectives.com/ 2017/10/17/considerations-when-treating-natural-disaster-victims-throughtelemental-telebehavioral-health-programs/\#. Accessed October 17, 2017.

4. Qadir TF, Usmani MH, Hussain SA. Telepsychiatry in Pakistan after natural disasters. Lancet Psychiatry. 2016;3:1016.

5. Garshnek V, Burkle FM. Applications of telemedicine and telecommunications to disaster medicine: historical and future perspectives. JAMA. 1999;6:26-37.

6. Uscher-Pines L, Fischer S, Tong I, et al. Virtual first responders: the role of direct-to-consumer telemedicine in caring for people impacted by natural disasters. J Gen Intern Med. 2018;33(8):1242-1244.

7. Vo AH, Brookes GB, Bourdeau M, et al. University of Texas Medical Branch Telemedicine Disaster Response and Recovery: lessons learned from Hurricane Ike. Telemed J E Health. 2010;16(5):627-633.

8. Lagasse J. Doctor on Demand, MDLIVE offer free video visit to victims. MobiHealthNews. Published 2017. https://www.mobihealthnews.com/ content/doctor-demand-mdlive-offer-free-video-visits-victims-hurricaneharvey. Accessed October 9, 2018.

9. Wicklund E. With new Texas law, telemedicine passes an important milestone. mHealth Intelligence. Published 2017. https://mhealthintelligence. com/news/with-new-texas-law-telemedicine-passes-an-important-milestone. Accessed October 9, 2018.

10. Muoio D. In-depth: recent hurricanes show that with proper preparation, telemedicine shines during disasters. MobiHealthNews. Published 2017. https:/www.mobihealthnews.com/content/depth-recent-hurricanes-showproper-preparation-telemedicine-shines-during-disasters. Accessed October 3, 2018. 
11. Siwicki B. New York Presbyterian specialists use telemedicine to treat stranded Puerto Ricans. Healthcare IT News. Published November 9, 2017. https://www.healthcareitnews.com/news/newyork-presbyterianspecialists-use-telemedicine-treat-stranded-puerto-ricans. Accessed October 9, 2018.

12. Doarn CR, Merrell RC. Telemedicine and e-health in disaster response. Telemed J E Health. 2014;20(7):605-606.

13. Doarn CR, Latifi R, Poropatich RK, et al. Development and validation of telemedicine for disaster response: The North Atlantic Treaty Organization Multinational System. Telemed J E Health. 2018;24(9):657-668.

14. Xiong W, Bair A, Sandrock C, et al. Implementing telemedicine in a medical emergency response: concept of operation for a regional telemedicine hub. J Med Syst. 2012;36:1651-1660.

15. Jasanoff $S$. The ethics of invention: technology and the human future. New York: W. W. Norton; 2016.

16. Jennings B. Disaster planning and public health. In: Crowley M, ed. From Birth to Death and Bench to Clinic: The Hastings Center Bioethics Briefing Book for Journalists, Policymakers and Campaigns. Garrison, NY: The Hastings Center; 2008:41-44.

17. Martinez KA, Rood M, Jhangiani N, et al. Association between antibiotic prescribing for respiratory tract infections and patient satisfaction in direct-to-consumer telemedicine. JAMA Intern Med. 2018;178(11): $1558-1560$

18. Martinez KA, Rood M, Jhangiani N, et al. Antibiotic prescribing for respiratory tract infections and encounter length: an observational study of telemedicine. Ann Intern Med. 2018;170(4):275-277.

19. Annas GJ. Ethical issues in disaster medicine. In: Koenig KL, Schultz CH, eds. Disaster Medicine: Comprehensive Principles and Practice. New York: Cambridge University Press; 2016:81-92.

20. Cohn D. Census: computer ownership, Internet connection varies widely across U.S. Published 2014. http://www.pewresearch.org/fact-tank/2014/09/ 19/census-computer-ownership-internet-connection-varies-widely-acrossu-s/. Accessed October 24, 2018.

21. Irvine R. Mediating telemedicine: ethics at a distance. Intern Med J. 2005;35:56-58.

22. McConnochie KM. Webside manner: a key to high-quality primary care telemedicine for all. Telemed J E Health. 2019;25(11):1007-1011.

23. Association of American Medical Colleges. Content documentation in required courses and elective courses. Published 2020. https:// www.aamc.org/data-reports/curriculum-reports/interactive-data/contentdocumentation-required-courses-and-elective-courses. Accessed January 20, 2020

24. Tuckson RV, Edmunds M, Hodgkins M. Telehealth. N Engl J Med. 2017;377(16):1585-1592.

25. Federation of State Medical Boards. Telemedicine policies: board by board overview. Published November 2019. http://www.fsmb.org/siteassets/ advocacy/key-issues/telemedicine_policies_by_state.pdf. Accessed November 29, 2018.

26. American College of Emergency Physicians. Ethical use of telemedicine in emergency care. Ann Emerg Med. 2016;68(6):791.

27. Chaudhry HJ, Robin LA, Fish EM, et al. Improving access and mobility the Interstate Medical Licensure Compact. N Engl J Med. 2015; 372(17):1581-1583.
28. Interstate Medical Licensure Compact Commission. Interstate Medical Licensure Compact: a faster pathway to medical licensure. Published 2018. https://imlcc.org/. Accessed November 13, 2018.

29. National Emergency Management Association. What is EMAC? Published 2018. https:/www.emacweb.org/index.php/learn-about-emac/ what-is-emac. Accessed July 15, 2020.

30. Emergency Management Assistance Compact of 1996. Public law 104-321. https:/www.govinfo.gov/content/pkg/PLAW-104publ321/pdf/PLAW104publ321.pdf. Accessed July 15, 2020.

31. Boyajian-O'Neill LA, Gronewold LM, Glaros AG, et al. Physician licensure during disasters: a national survey of state medical boards. JAMA. 2008;299(2):169-171.

32. Iserson KV, Heine CE. Bioethics. In: Walls RM, Hockberger RS, GauscheHill M, et al., eds. Rosen's Emergency Medicine: Concepts and Clinical Practice. Philadelphia: Elsevier; 2018.

33. Siwicki B. Comparing 11 top telehealth platforms: company execs tout quality, safety, EHR integrations. Healthcare IT News. 2017. https://www. healthcareitnews.com/news/comparing-11-top-telehealth-platformscompany-execs-tout-quality-safety-ehr-integrations. Accessed December 10,2018

34. Department of Health and Human Services. Hurricane Dorian \& HIPAA Bulletin: limited waiver of HIPAA sanctions and penalties during a declared emergency. Published 2019. https://www.hhs.gov/sites/default/ files/hurricane-dorian-hipaa-bulletin.pdf. Accessed January 20, 2020.

35. Pols J. Towards an empirical ethics in care: relations with technologies in health care. Med Health Care Philos. 2015;182015:81-90.

36. Council on Ethical and Judicial Affairs. Opinions on confidentiality, advertising and communications media relations. Code Med Ethics Am Med Assoc. 2015:155-200.

37. Naess A-C, Foerde R, Steen PA. Patient autonomy in emergency medicine. Med Health Care Philos. 2001;4:71-77.

38. MDLive. In times of crisis, we're better together. Published 2017. http:// www3.mdlive.com/harveypr. Accessed October 3, 2018.

39. Doctor on Demand. Helping those affected by Hurricane Harvey. Doctor on Demand. Published August 30, 2017. https://blog.doctorondemand. $\mathrm{com} /$ helping-those-affected-by-hurricane-harvey-b129890fe57b. Accessed July 15, 2020.

40. Chaet D, Clearfield R, Sabin JE, et al. Ethical practice in telehealth and telemedicine. J Gen Intern Med. 2017;32(10):1136-1140.

41. AMA Council on Ethical and Judicial Affairs. Opinions on the patient-physician relationship. Code Med Ethics Am Med Assoc. 2015: 329-423.

42. Jesus JE. Is third world health care different? (reply). Ann Emerg Med. 2010;56(3):308-309.

43. Buckmon K. Modernizing the National Disaster Medical System to meet the health security threats of the 21st century. ASPR Blog. Published September 4, 2018. https://www.phe.gov/ASPRBlog/Pages/default2.aspx. Accessed January 20, 2020.

44. National Emergency Management Association. An analysis of EMAC capabilities for private sector and volunteer resource coordination. https:/www.emacweb.org/index.php/mutualaidresources/emac-library/bestpractices/private-sector-deployments-through-emac/5-emac-private-sectorand-volunteer-resources-analysis. Accessed December 1, 2018. 